\title{
Differences in lung function between children with sickle cell anaemia from West Africa and Europe
}

\author{
Michele Arigliani (D) ,' Luigi Castriotta, ${ }^{2}$ Ramatu Zubair, ${ }^{3}$ Livingstone Gayus Dogara, ${ }^{4}$ \\ Chiara Zuiani, ${ }^{1}$ Emma Raywood (10 , ${ }^{5}$ Katy Vecchiato, ${ }^{6}$ Enrico Petoello, ${ }^{7}$ \\ Ashel Dache Sunday, ${ }^{3}$ Sharon Ndoro, ${ }^{8}$ Mario Canciano Canciani, ${ }^{1}$ Atul Gupta, ${ }^{9}$ \\ Paola Cogo, ${ }^{1}$ Baba Inusa ${ }^{8}$
}

\begin{abstract}
- Additional material is published online only. To view, please visit the journal online (http://dx.doi.org/10.1136/ thoraxjnl-2019-213717).
\end{abstract}

For numbered affiliations see end of article.

\section{Correspondence to}

Dr Michele Arigliani, Division of Pediatrics, University Hospital of Udine, Piazzale S. Maria Misericordia 1, 33100 Udine, Italy;

michelearigliani@gmail.com

Received 15 June 2019 Revised 22 August 2019

Accepted 25 September 2019

Published Online First

17 October 2019

\section{Check for updates}

(c) Author(s) (or their employer(s)) 2019. No commercial re-use. See rights and permissions. Published by BMJ.

To cite: Arigliani $\mathrm{M}_{\mathrm{t}}$ Castriotta L, Zubair $\mathrm{R}$, et al.

Thorax 2019;74:1154-1160.

\begin{abstract}
Introduction Lung function abnormalities are common in sickle cell anaemia (SCA) but data from sub-Saharan Africa are limited. We hypothesised that children with SCA from West Africa had worse lung function than their counterparts from Europe.

Methods This prospective cross-sectional study evaluated spirometry and anthropometry in black African individuals with SCA (haemoglobin phenotype SS) aged 6-18 years from Nigeria and the UK, when clinically stable. Age-matched controls were also included in Nigeria to validate the Global Lung Initiative spirometry reference values.
\end{abstract}

Results Nigerian SCA patients $(n=154)$ had significant reductions in both FEV and FVC of $\sim 1 \mathrm{z}$-score compared with local controls $(n=364)$ and $\sim 0.5$ z-scores compared with the UK patients $(n=101)$. Wasting (body mass index $z$-score $<-2$ ) had a prevalence of $27 \%$ in Nigerian patients and $7 \%$ in the UK ones $(p<0.001)$. Among children with SCA, being resident in Nigeria (OR 2.4, $95 \% \mathrm{Cl} 1.1$ to 4.9 ), wasting (OR $2.3,95 \% \mathrm{Cl} 1.1$ to 5.0 ) and each additional year of age (OR 1.2, 95\% Cl 1.1 to 1.4) were independently associated with increased risk of restrictive spirometry (FVC z-score $<-1.64+\mathrm{FEV}_{1}$ / $F V(\geq-1.64)$.

Conclusions This study showed that chronic respiratory impairment is more severe in children with SCA from West Africa than Europe. Our findings suggest the utility of implementing respiratory assessment in African children with SCA to early identify those with chronic lung injury, eligible for closer follow-up and more aggressive therapies.

\section{INTRODUCTION}

Respiratory complications and lung function abnormalities are common in patients with sickle cell anaemia (SCA). ${ }^{1}$ However, there are limited data from sub-Saharan Africa, where over 200000 children with this condition are born each year. ${ }^{2}$ Chronic respiratory impairment in SCA has a multifactorial pathogenesis and involves both parenchymal, airways and vascular abnormalities. ${ }^{1}$ Patients generally experience a decline of lung function with age, ${ }^{3-6}$ and a restrictive pattern may appear in childhood, ${ }^{3}$ becoming common in adulthood. ${ }^{7}$ However, among paediatric patients with SCA living in high-income countries (HICs), obstructive lung function is more frequent than

\section{Key messages}

What is the key question?

- Lung function abnormalities are common in sickle cell anaemia (SCA) but it has never been investigated whether there are differences in the degree of respiratory impairment between children with this condition living in West Africa and Europe.

What is the bottom line?

- Children with SCA from West Africa have worse spirometry outcomes and higher prevalence of a restrictive spirometry pattern compared with their counterparts from Europe.

Why read on?

- This is the first study comparing lung function in children with SCA living in West Africa and Europe, and it shows important differences in the degree of respiratory impairment between the two populations, implying the need of implementing lung function assessment in patients with SCA in West Africa.

restrictive. ${ }^{8-10}$ Spirometry results have a prognostic meaning in adults with SCA, as a low $\mathrm{FEV}_{1}$ is associated with earlier mortality. ${ }^{7}$ Regarding risk factors for abnormal lung function in paediatric SCA patients, some studies pointed out an association with a history of acute chest syndrome $(\mathrm{ACS})^{31112}$ but other did not, ${ }^{8-10}$ whereas the rate of pain crises seems to be unrelated to respiratory abnormalities. ${ }^{8}{ }^{10}$ Malnutrition is associated with increased risk of restrictive spirometry pattern in children with SCA from Central Africa, ${ }^{13}$ while the body mass index (BMI) percentile was found to be an independent predictor of increase in $\mathrm{FEV}_{1}$ in patients from HICs. ${ }^{14}$

Although limited evidence is available, it seems that lung function abnormalities are highly prevalent in paediatric patients with SCA from subSaharan Africa, ${ }^{12} 131516$ with restrictive spirometry being the most frequent pathological pattern. ${ }^{13}$ The burden of respiratory disease in children with SCA living in low-middle income countries (LMICs) and HICs has not been previously compared. This evaluation could be useful because, if substantial 
differences were found, respiratory care of SCA patients in the two settings should be tailored to the local epidemiology.

In this cross-sectional study, we investigated lung function, through spirometry, in black African paediatric patients with SCA from Nigeria and the UK. Age-matched healthy controls were also included in Nigeria. We hypothesised that SCA-related chronic lung disease was more severe in paediatric patients from West Africa than in their counterparts from Europe, resulting in lower spirometry z-scores and higher prevalence of restrictive spirometry in the former.

\section{METHODS}

Parental consent from each participant was obtained before assessments.

Black African individuals with SCA (haemoglobin phenotype SS) aged 6-18 years were consecutively enrolled between March 2016 and September 2017 during a follow-up appointment in two SCA clinic either at the Evelina London Children's Hospital, UK, or the Barau Dikko Teaching Hospital, Kaduna, Nigeria. Both the hospitals are considered tertiary care centres for SCA in their countries. The study groups included patients of different socioeconomic status (SES), mainly living in urban areas and grossly representative of children with SCA followed at tertiary care in their countries, who are the majority in the $\mathrm{UK}^{17}$ but a minority in Nigeria. ${ }^{18}$ In the UK, only black African patients who had lived steadily in the country for the last 5 years were included. A control group of age-matched children and adolescents was enrolled in four schools in Kaduna state, Nigeria (details in online supplementary data), to verify whether the Global Lung Initiative 2012 (GLI-2012) reference values for spirometry fitted that population. In the UK, healthy controls were not enrolled, since the GLI-2012 had been previously validated for children of black African origin. ${ }^{19}$

Individuals who had respiratory symptoms or felt unwell on the test day and those who performed a low-quality spirometry $^{2021}$ were excluded. Patients who had experienced SCArelated acute events (eg, pain crises) in the last month were also excluded. Details on sample size calculation are provided in online supplementary data.

\section{Questionnaires}

Caregivers of patients with SCA were interviewed by one of the investigators regarding frequency of pain crises in the last 12 months (bone pain in the chest, extremities or other areas that required at least 24 hours of analgesic therapy). A history of asthma was identified according to parent's report or evidence from medical record of physician-diagnosed asthma ever. Information on hydroxyurea therapy and previous ACS episodes (fever and/or respiratory symptoms, accompanied by a new pulmonary infiltrate on a chest X-ray ${ }^{22}$ ) was taken from medical records.

Environmental factors that could have an impact on respiratory health, such as SES, tobacco smoke exposure and the type of fuel most frequently used for cooking at home, were also investigated. SES was evaluated using a modified version of the Family Affluence Scale (FAS) ${ }^{23}$ (details in online supplementary data).

\section{Assessments}

Height and weight were measured according to a standardised protocol (details in online supplementary data). Z-scores for height (zHeight) and BMI (zBMI) were derived using published reference equation. ${ }^{24}{ }^{25}$ Wasting was defined as $\mathrm{zBMI}<-2$ $(<2.5$ th percentile $)$ and stunting as a zHeight $<-2$. An Easy
on-PC ultrasonic flowmeter spirometer (ndd, Zurich, Switzerland) was used and $95 \%$ of spirometry tests were performed by the principal investigator. Quality control was performed according to European Respiratory Society standards adapted for children ${ }^{2021}$ and over-reading was carried out by a blinded trained investigator. Spirometry z-scores for $\mathrm{FEV}_{1}, \mathrm{FVC}$ and $\mathrm{FEV}_{1} / \mathrm{FVC}$ were derived according to the GLI-2012 reference equations for African-Americans. ${ }^{26} \mathrm{~A}$ z-score indicates how many SDs a measurement differs from the predicted value. The lower limit of normal (LLN) for spirometry was established at $-1.64 \mathrm{z}$-scores (5th percentile) of the reference population. ${ }^{27}$ Spirometry patterns were classified as normal (FVC and $\mathrm{FEV}_{1} /$ $\mathrm{FVC} \geq \mathrm{LLN}$ ), obstructive (FVC $\geq \mathrm{LLN}$ and $\mathrm{FEV}_{1} / \mathrm{FVC}<\mathrm{LLN}$ ), restrictive $\left(\mathrm{FVC}<\mathrm{LLN}\right.$ and $\left.\mathrm{FEV}_{1} / \mathrm{FVC} \geq \mathrm{LLN}\right)$ or mixed $\left(\mathrm{FEV}_{1} /\right.$ FVC and FVC $<$ LLN).

\section{Statistical analysis}

Normality of distribution was assessed by the Shapiro-Wilk test. Group comparisons were performed using unpaired $t$-test, Wilcoxon rank-sum test, $\chi^{2}$ test or Fisher's exact test as appropriate. Regression analyses were restricted to SCA patients. The association between being resident in Nigeria (vs the UK) and a restrictive spirometry pattern (vs 'normal') was evaluated through a multivariable logistic regression model including several potential confounders (ie, sex, age, zBMI $<-2$, absence of hydroxyurea therapy, previous ACS and at least three pain crises in the last year). The same covariates (except for zBMI that was here considered as a continuous variable) were also tested in multivariable linear regression models for $\mathrm{FEV}_{1}$ and FVC z-scores. Covariates selection was carried out through a stepwise backward approach, by retaining in the final model variables with a $\mathrm{p}$ value $<0.2$ (saturated models are presented in online supplementary data). Validity of regression assumptions and the models' fit were assessed through the analysis of residuals, the Cameron and Trivedi's decomposition of information matrix test and the Hosmer-Lemeshow goodness-of-fit test. A p value $<0.05$ was considered as statistically significant. All analyses were conducted using Stata V.14 software.

\section{RESULTS}

\section{General characteristics of the study population}

A total of 186 individuals with SCA in Nigeria and 122 in the UK were recruited. After exclusions (figure 1), data from 154 patients in Nigeria and 101 in the UK were analysed. Among patients enrolled in the UK, 82\% (83/101) had West African origins (born in the UK or overseas), while the others were originally from different countries of Central and East Africa. Clinical characteristics of SCA patients are resumed in table 1.

Distribution by age and sex was similar in the two groups of SCA patients (see online supplementary table E1). Among controls, 15/434 (3\%) were excluded for the presence of respiratory symptoms and 55/434 (13\%) for low-quality spirometry, with 364 individuals left in the final analysis (table 2).

Frequency of low SES (FAS score 0-1 out of 6) in Nigeria was $52 \%$ in SCA patients, $52 \%$ in controls, and $17 \%$ among patients with SCA in the UK $(\mathrm{p}<0.001$ compared with Nigerian SCA group) (see online supplementary table E2). Passive smoking was recorded in 9\% of SCA patients in Nigeria and 12\% in the UK $(p=0.4)$. Almost half $(49 \%)$ of Nigerian patients used solid fuels for cooking (37\% wood, $10 \%$ coal and $1 \%$ animal dung), whereas the other patients in Nigeria and in the UK used nonsolid fuels (see online supplementary table E2). 


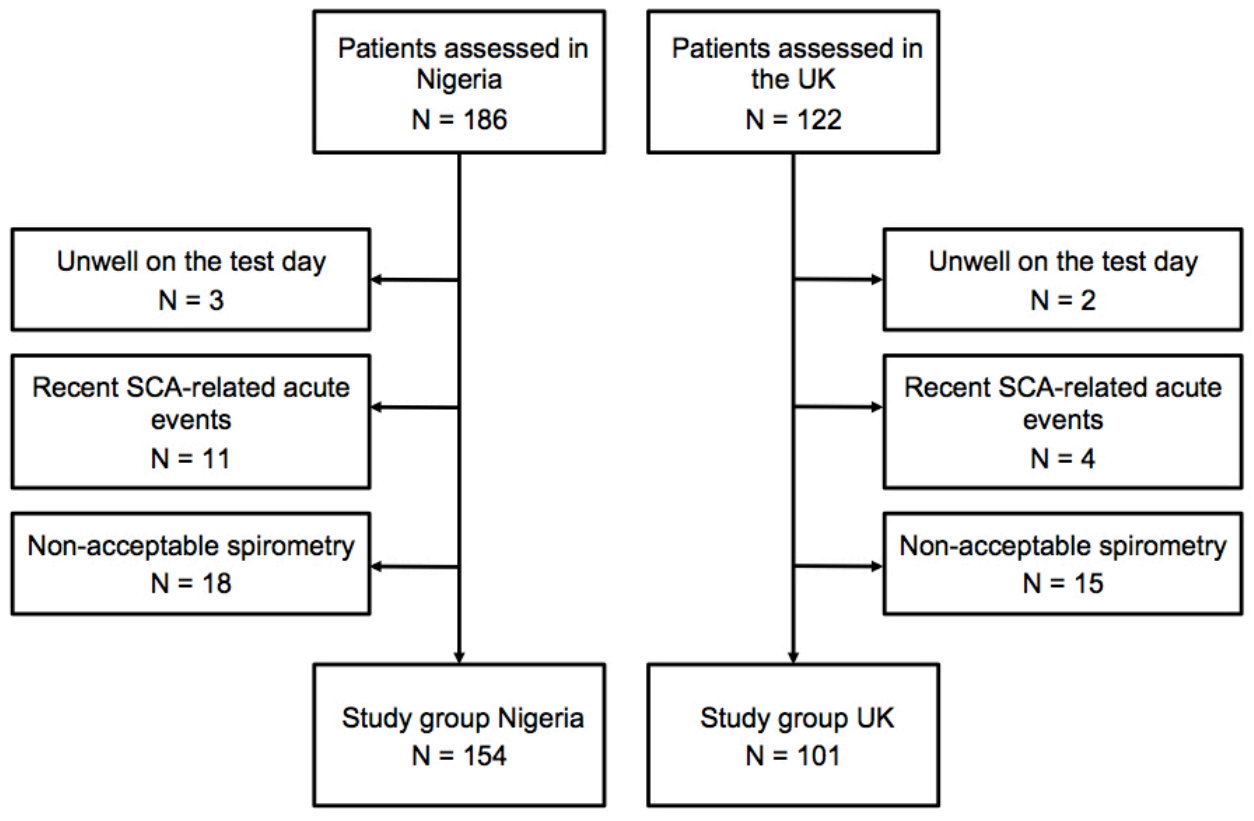

Figure 1 Study groups. Patients with sickle cell anaemia (SCA) aged 6-18 years from two tertiary care centres in Nigeria and the UK.

\section{Lung function and nutritional status in SCA patients and controls}

Children and adolescents with SCA in Nigeria had lower spirometry and markedly lower anthropometry z-scores than those from the UK (table 2). The proportion of patients with $\mathrm{FEV}_{1}<5$ th percentile of predicted was $38 \%$ in Nigeria and $27 \%$ in the UK $(p=0.05)$.

Most children and adolescents with SCA in both countries had normal spirometry (62\% in Nigeria and $70 \%$ in the UK, $\mathrm{p}=0.19$ ) (figure 2). Prevalence of a restrictive spirometry pattern was more than double in the Nigerian SCA group than in the UK one ( $30 \%$ vs $14 \%, p=0.008)$, whereas there were no significant differences in the frequency of an obstructive pattern $(5 \%$ vs $9 \%, \mathrm{p}=0.4)$ and a mixed obstructive/restrictive pattern (3\% vs $7 \%, \mathrm{p}=0.11)$.

Mean $\mathrm{FEV}_{1}$ and FVC values in Nigerian controls were within -0.3 z-scores from predicted with SD close to 1 , while mean (SD) $\mathrm{FEV}_{1} / \mathrm{FVC} \mathrm{z}$-score was -0.08 (0.88) (table 2). Prevalence of pathological spirometry patterns in controls was $8 \%$ restrictive, $4 \%$ obstructive and $0.5 \%$ mixed.

Stunting had a prevalence of $41 \%$ in patients with SCA in Nigeria, $23 \%$ in local controls $(\mathrm{p}<0.001)$ and $5 \%$ in the UK SCA group (figure 3). Wasting was found in $27 \%$ of patients

\begin{tabular}{|c|c|c|c|}
\hline Variable & $\begin{array}{l}\text { SCA UK } \\
(\%)\end{array}$ & $\begin{array}{l}\text { SCA NIG } \\
(\%)\end{array}$ & $P$ value \\
\hline Current hydroxyurea treatment & 47.5 & 0.6 & $<0.001$ \\
\hline Asthma* & 21.7 & 6.7 & $<0.001$ \\
\hline At least three pain crises in the last yeart & 24.7 & 49.3 & $<0.001$ \\
\hline Previous acute chest syndrome $\ddagger$ & 34.5 & 21.4 & 0.02 \\
\hline
\end{tabular}

*Parent report or medical record evidence of physician-diagnosed asthma.

tPain crises requiring analgesic therapy for at least 24 hours.

\#Fever and/or respiratory symptoms, accompanied by a new pulmonary infiltrate on a chest X-ray. ${ }^{22}$ in Nigeria, $10 \%$ of controls $(\mathrm{p}<0.001)$ and $7 \%$ of the UK SCA group (figure 3).

\section{Factors associated with lung function impairment in patients with SCA}

At multivariable logistic regression in children with SCA, being resident in Nigeria (OR 2.4, 95\% CI 1.1 to 4.9), each additional year of age (OR 1.2, 95\% CI 1.1 to 1.4 ) and wasting (OR 2.3, $95 \%$ CI 1.1 to 5.0 ) were independently associated with increased risk of restrictive spirometry (adjusted $\mathrm{R}^{2}=0.12$ ) (table 3 ). Only these variables, along with a history of ACS, were retained in the final model, whereas the covariates 'male sex', 'no hydroxyurea therapy' and 'at least three pain crises in the last 12 months' were excluded according to a stepwise backward approach based on a $\mathrm{p}$ value $<0.2$.

At multivariable linear regression analyses, increasing age, BMI z-score and a history of ACS also had a significant impact on both $\mathrm{FEV}_{1} \mathrm{z}$-score (adjusted $\mathrm{R}^{2}=0.25$ ) and FVC $\mathrm{z}$-score (adjusted $\mathrm{R}^{2}=0.27$ ) of patients with SCA (table 4 ).

There were no significant interactions among variables included in the logistic and linear regression models (data not shown).

There were no statistically significant differences in the prevalence of pathological spirometry patterns in Nigerian and the UK SCA patients according to SES, tobacco smoke exposure and, in Nigeria, the use of solid fuels versus non-solid fuels for cooking at home (data not shown).

\section{DISCUSSION}

This study showed that black African paediatric patients with SCA living in a LMICs setting had significant reductions of approximately $0.5 \mathrm{z}$-scores in both $\mathrm{FEV}_{1}$ and $\mathrm{FVC}$ and a more frequent restrictive spirometry pattern compared with their counterparts resident in a HICs setting (30\% vs $14 \%, \mathrm{p}=0.008)$.

An obstructive pattern was more common among patients from the UK than Nigeria ( $9 \%$ vs 5\%), though the difference was not significant $(p=0.4)$. In studies performed in HICs, airflow limitation is a common finding at spirometry in children with SCA. ${ }^{8-10}$ Airway inflammation and remodelling related to 
Table 2 Anthropometric and spirometry z-scores in patients aged 6-18 years with sickle cell anaemia (SCA) from the UK and Nigeria (NIG)

\begin{tabular}{|c|c|c|c|c|}
\hline & SCA UK & SCA NIG & $\begin{array}{l}\text { Mean difference UK-NIG } \\
\text { ( } 95 \% \mathrm{Cl} ; \mathrm{p} \text { value) }\end{array}$ & Controls NIG \\
\hline $\mathrm{N}$ (\% male) & $101(51 \%)$ & $154(54 \%)$ & & $364(52 \%)$ \\
\hline Age, years & $11.7(2.7)$ & $11.4(3.2)$ & $0.3(-0.5$ to $1.0 ; 0.12)$ & $10.4(2.4)$ \\
\hline zHeight & $0.23(1.25)$ & $-1.77(1.21)$ & $2.00(1.68$ to $2.30 ;<0.001)$ & $-0.75(1.51)$ \\
\hline zBMI & $0.12(1.23)$ & $-1.49(1.08)$ & $1.61(1.32$ to $1.90 ;<0.001)$ & $-0.62(1.32)$ \\
\hline $\mathrm{zFEV}_{1}$ & $-0.97(1.06)$ & $-1.38(0.96)$ & $0.41(0.15$ to $0.66 ; 0.01)$ & $-0.35(0.99)$ \\
\hline $\mathrm{FEV}_{1} \%$ & $87.1(14.2)$ & $81.9(13.3)$ & 5.1 (1.7 to $8.6 ; 0.003)$ & $95.2(13.0)$ \\
\hline zFVC & $-0.68(1.06)$ & $-1.21(0.96)$ & $0.53(0.28$ to $0.78 ;<0.001)$ & $-0.31(0.97)$ \\
\hline FVC\% & $91.1(13.5)$ & $84.3(12.7)$ & 6.8 (3.3 to $9.8 ;<0.001)$ & $95.9(12.4)$ \\
\hline $\mathrm{zFEV}_{1} / \mathrm{FVC}$ & $-0.68(0.97)$ & $-0.47(0.83)$ & $-0.20(-0.42$ to $0.02 ; 0.07)$ & $-0.08(0.88)$ \\
\hline
\end{tabular}

Results are presented as mean (SD), unless otherwise specified.

zBMI and zHeight values are based on WHO growth charts. ${ }^{25}$

Spirometry z-scores and \% predicted are based on Global Lung Function Initiative 2012 equations for African-Americans. ${ }^{26}$

FEV $\%$, \% predicted; FVC\%, \% predicted; zBMI, z-score body mass index; zFEV , z-score FEV $;$; zFEV, /FVC, z-score FEV,/FVC; zFVC, z-score FVC; zHeight, z-score height.

vaso-occlusion and haemolysis in the pulmonary microcirculation, ${ }^{1}$ together with pulmonary vessel engorgement causing compression of the distal airways, ${ }^{28}$ could be the basis of this finding. Studies on adolescents and adults with SCA, however, show that a restrictive physiology becomes prominent with increasing age, ${ }^{72} 30$ probably as a consequence of cumulative lung injury. The predominance of a restrictive spirometry pattern over an obstructive one in children with SCA from Nigeria recalls the findings of older SCA patients in $\mathrm{HICs}^{7}$ and probably reflects a more advanced stage of chronic lung disease than in children with SCA from the UK.

Comparison of our findings with those of previous studies on children with SCA is hampered by the fact that many different spirometry reference values and criteria for defining lung function abnormalities have been used. ${ }^{49101516}$ Two recent studies adopting the GLI-2012 reference values reported frequencies of restrictive and obstructive spirometry patterns in children with SCA from HICs and LMICs settings, respectively, similar to those of the present study. ${ }^{813}$

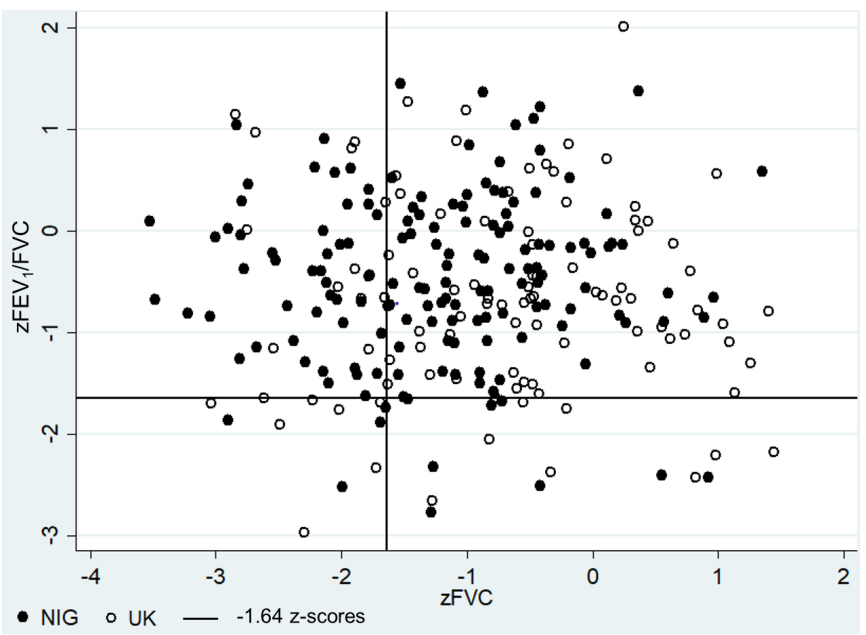

Figure 2 Scatter plot of $\mathrm{FEV}_{1} / \mathrm{FVC}$ versus FVC z-scores in children aged 6-18 years with sickle cell anaemia from Nigeria (NIG) (black dots, $n=154$ ) and the UK (white dots, $n=101$ ). The continuous lines represent -1.64 z-scores. Z-scores were derived from the Global Lung Function Initiative 2012 equations for African-Americans. ${ }^{26}$
Asthma was more frequent in the UK SCA group than in the Nigerian one. Asthma is reported in 15\%-28\% of people with SCA living in HICs, ${ }^{31}$ whereas we found that less than $10 \%$ of SCA patients in the Democratic Republic of Congo (Central Africa ${ }^{13}$ and Nigeria (West Africa) had a physician's diagnosis of asthma. Some of these children could have been underdiagnosed, due to poor healthcare access in sub-Saharan Africa. ${ }^{32}$ On the other side, though overdiagnosis of paediatric asthma is common in the primary care setting in HICs, ${ }^{33}$ that should not be the case for SCA patients enrolled in the UK, most of whom had been reviewed by a respiratory paediatrician and had an asthma diagnosis based on the integration of clinical history information and objective investigations. Overall, from our findings, it seems that asthma is less common in children with SCA from sub-Saharan Africa than in those from HICs. These differences could be related to a lower asthma prevalence in the general African population, which is estimated at 5.9\% in the urban setting, although with high variability between countries. $^{34}$

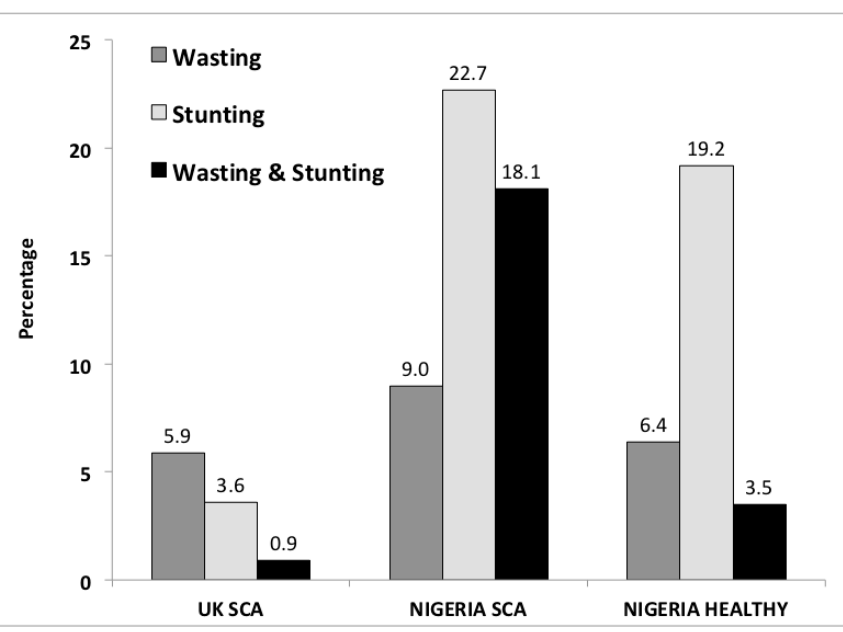

Figure 3 Prevalence of wasting (BMI z-score $<-2$ ), stunting (height $z$-score $<-2$ ) and the combination of both in patients with sickle cell anaemia (SCA) from the UK $(n=101)$, Nigeria $(n=154)$ and healthy controls in Nigeria $(n=364)$, aged $6-18$ years. Anthropometry z-scores are based on WHO growth charts. BMI, body mass index. ${ }^{25}$ 
Table 3 Multivariable logistic regression for restrictive spirometry pattern (vs normal) in 223 paediatric patients with sickle cell anaemia from Nigeria and the UK

\begin{tabular}{|c|c|c|}
\hline Covariate* & $\begin{array}{l}\text { Crude OR } \\
(95 \% \mathrm{Cl} ; \mathrm{p} \text { value })\end{array}$ & $\begin{array}{l}\text { Adjusted OR } \\
\text { (95\% Cl; } p \text { value) }\end{array}$ \\
\hline Residency in Nigeria (vs the UK) & $\begin{array}{l}2.4 \\
(1.2 \text { to } 4.7 ; 0.01)\end{array}$ & $\begin{array}{l}2.4 \\
\text { (1.1 to } 4.9 ; 0.02)\end{array}$ \\
\hline Age, years & $\begin{array}{l}1.2 \\
(1.1 \text { to } 1.3 ;<0.001)\end{array}$ & $\begin{array}{l}1.2 \\
(1.1 \text { to } 1.4 ;<0.001)\end{array}$ \\
\hline $\mathrm{zBMl}<-2$ & $\begin{array}{l}2.9 \\
(1.4 \text { to } 5.8 ; 0.003)\end{array}$ & $\begin{array}{l}2.3 \\
\text { (1.1 to } 5.0 ; 0.03 \text { ) }\end{array}$ \\
\hline Previous acute chest syndrome $\dagger$ & $\begin{array}{l}1.6 \\
\text { (0.9 to } 3.0 ; 0.13 \text { ) }\end{array}$ & $\begin{array}{l}1.7 \\
\text { (0.8 to } 3.2 ; 0.12)\end{array}$ \\
\hline
\end{tabular}

zBMI values are based on WHO growth charts. ${ }^{25}$

Spirometry z-scores are based on Global Lung Function Initiative 2012 equations for African-Americans. $^{26}$

Restrictive spirometry pattern $=\mathrm{FVC}<\mathrm{LLN}$ and $\mathrm{FEV}, / F V C \geq \mathrm{LLN}$.

Adjusted $\mathrm{R}^{2}$ of the model $=0.12$.

* Only covariates with a $p$ value $<0.2$ were retained in the final model. The initial model also included the covariates: 'male sex', 'no hydroxyurea therapy' and 'at least three pain crises in the last 12 months' (saturated models are presented in online supplementary data).

†Fever and/or respiratory symptoms, plus a new pulmonary infiltrate on a chest $\mathrm{X}$-ray. ${ }^{22}$

LLN, lower limit of normal; zBMI, z-score body mass index.

The GLI-2012 reference values fitted Nigerian children and adolescents adequately, as the mean spirometry z-scores in controls were within $-0.3 \mathrm{z}$-scores from predicted with an SD of nearly $1 .^{26}$ Paediatric SCA patients in Nigeria had marked reductions of $1.03 \mathrm{z}$-scores (13\% of predicted) in $\mathrm{FEV}_{1}$ and $0.90 \mathrm{z}$-scores (11\% of predicted) in FVC compared with local controls (table 2). Despite the use of different reference values precluding accurate comparison with other studies, low spirometry results have been consistently reported in African children

Table 4 Multivariable linear regression models for $\mathrm{FEV}_{1}$ and FVC z-scores in 255 patients with sickle cell anaemia aged $6-18$ years from Nigeria $(n=154)$ and the UK $(n=101)$

\begin{tabular}{|c|c|c|}
\hline & FEV $_{1}$ z-scoret & FVC z-scoret \\
\hline Covariate* & $\begin{array}{l}\text { Adjusted B } \\
\text { (95\% Cl; } p \text { value) }\end{array}$ & $\begin{array}{l}\text { Adjusted B } \\
\text { (95\% Cl; } p \text { value) }\end{array}$ \\
\hline Male sex & $\begin{array}{l}0.26 \\
(0.04 \text { to } 0.49 ; 0.02)\end{array}$ & $\begin{array}{l}0.20 \\
(-0.18 \text { to } 0.42 ; 0.07)\end{array}$ \\
\hline Age, years & $\begin{array}{l}-0.09 \\
(-0.12 \text { to }-0.05 ;<0.001)\end{array}$ & $\begin{array}{l}-0.08 \\
(-0.11 \text { to }-0.04 ;<0.001)\end{array}$ \\
\hline zBMI & $\begin{array}{l}0.26 \\
(0.17 \text { to } 0.35 ;<0.001)\end{array}$ & $\begin{array}{l}0.29 \\
(0.21 \text { to } 0.38 ;<0.001)\end{array}$ \\
\hline No hydroxyurea therapy & $\begin{array}{l}-0.27 \\
(-0.59 \text { to } 0.04 ; 0.09)\end{array}$ & $\begin{array}{l}-0.30 \\
(-0.62 \text { to } 0.00 ; 0.05)\end{array}$ \\
\hline $\begin{array}{l}\text { Previous acute chest } \\
\text { syndrome } \neq\end{array}$ & $\begin{array}{l}-0.41 \\
(-0.67 \text { to }-0.17 ; 0.001)\end{array}$ & $\begin{array}{l}-0.35 \\
(-0.60 \text { to }-0.11 ; 0.004)\end{array}$ \\
\hline
\end{tabular}

zBMI values are based on WHO growth charts. ${ }^{25}$

Spirometry z-scores are based on Global Lung Function Initiative 2012 equations for African-Americans. ${ }^{26}$

* Only the variables presented in the table were retained in the final models, whereas the original models also included the covariates 'residency in Nigeria' and 'at least three pain crises in the last year' that were excluded through a stepwise backward approach based on a $p$ value $<0.2$.

†Adjusted $\mathrm{R}^{2}$ of the models: 0.25 for $\mathrm{ZFEV}_{1}$ and 0.27 for zFVC.

¥Fever and/or respiratory symptoms, plus a new pulmonary infiltrate on a chest X-ray. ${ }^{22}$

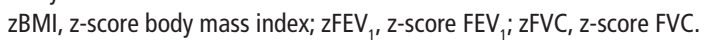

with SCA from the eastern, ${ }^{15}$ central $^{13}$ and western ${ }^{12} 16$ part of the continent. Conversely, most recent data from HICs, including our findings in the UK SCA group, show that patients living in this setting have higher dynamic lung volumes ${ }^{335}$ and narrower differences with controls ${ }^{36}$ compared with Nigerian patients. Overall, these findings suggest that chronic lung injury in children with SCA in HICs is milder than in sub-Saharan Africa. It is plausible that the disparities in healthcare provisions between the two settings play a role in these differences. In our study, for example, only one patient among those followed at a tertiary care centre in Nigeria had access to hydroxyurea therapy, which was shown to slow down lung function decline in paediatric SCA patients. $^{37}$

Risk factors for pathological spirometry in patients with SCA Being resident in Nigeria (vs the UK) was associated with a 2.4fold increased risk of restrictive spirometry among SCA patients (95\% CI 1.1 to 4.9). However, as most of UK patients had Nigerian origin, it is likely that the covariate 'being resident in Nigeria' was a proxy for other unmeasured risk factors, unrelated to genetic background. The above-mentioned differences in healthcare provisions between the UK and Nigeria might be among these risk factors, which should be further investigated in prospective studies.

Malnutrition, as indicated by the presence of wasting, affected almost one out of three Nigerian SCA patients $(27 \%)$ and was much more frequent than in local controls (10\%) and the UK patients (7\%). There is evidence indicating that malnutrition is common in children with SCA in sub-Saharan Africa ${ }^{13} 15$ and is associated with worse clinical outcomes. ${ }^{38}$ From our findings, nutritional status seems to have an impact on lung function in SCA patients, as the unitary increase of zBMI was associated with approximately $0.3 \mathrm{z}$-scores increases in $\mathrm{FEV}_{1}$ and FVC, while wasting was associated with a more than doubled risk of restrictive spirometry (OR $2.3,95 \% \mathrm{CI} 1.1$ to $5.0, \mathrm{p}=0.03$ ). The results are in line with those of previous studies reporting a positive association between BMI percentile and $\mathrm{FEV}_{1}{ }^{14}$ as well as an increased risk of restrictive spirometry pattern in SCA patients with wasting. ${ }^{13}$ There are several factors potentially implicated in the relationship between nutritional status and lung function in SCA patients. First of all, wasting could reflect increased metabolic demands due to a more severe course of disease ${ }^{38}$ including worse respiratory manifestations. Moreover, wasting could affect chest size ${ }^{39}$ and expiratory muscle strength, which was shown to be impaired in children with SCA. ${ }^{40}$

Increasing age was associated with a decline in spirometry $\mathrm{z}$-scores and increased risk of restrictive spirometry. Although the cross-sectional nature of this study does not allow to draw conclusions regarding lung function changes over time, these findings are consistent with those of longitudinal studies showing a decline of lung function with age in paediatric SCA patients, ${ }^{3-5}$ associated with a progressively increasing risk of restrictive lung abnormalities. $^{34}$

We found that a previous ACS episode had a negative impact on spirometry z-scores in children with SCA (table 4). However, since there is conflicting evidence from longitudinal studies, 335 the relationship between ACS and respiratory impairment in SCA patients should be further investigated, especially in subSaharan Africa where it has not been evaluated so far.

The use of hydroxyurea was not associated with better lung function outcomes. However, this could be expected on a cross-sectional evaluation, considering that patients initiated on hydroxyurea generally are those with higher rates of 
complications and a more severe course of disease. There is already published evidence that hydroxyurea improves longterm lung function outcomes in SCA patients living in HICs, ${ }^{37}$ while evidence is pending in the African setting.

Tobacco smoke exposure and use of biomass fuel for cooking at home did not affect lung function in SCA patients. These factors have a detrimental effect on spirometry indices in the general paediatric population ${ }^{41} 42$ that might have been covered by SCArelated respiratory impairment in our study. It is even possible that methodological limitations (eg, environmental information based on parent's report only; the impact of outdoor air pollution not evaluated; and the study not powered for this outcome) prevented to detect a possible impact of such environmental factors on lung function in children with SCA.

\section{Strenghts and limitations}

A strength of this study is that data collection was performed in two continents by the same principal investigator, using the same equipment and methodology. The validation of the GLI-2012 reference values for Nigerian children allowed a more accurate evaluation of spirometry results in patients with SCA from that country. The investigation of SES and sources of indoor pollution also allowed to evaluate the impact of important environmental factors on spirometry findings.

A limitation of this study is that the diagnosis of pathological respiratory patterns was only presumptive, in the absence of static lung volumes measurement. As known, cross-sectional studies usually cannot prove causality; therefore, especially for time-varying covariates, the associations found at regression analysis should be confirmed in longitudinal studies. The crosssectional design also prevents from evaluating whether the lower spirometry results in patients with SCA from Nigeria are tracked over time and their prognostic meaning. Finally, since patients from Nigeria were followed at a tertiary care centre, they are not representative of the entire paediatric SCA population of that country, where most patients do not have access to tertiary care. $^{18}$

\section{Future directions}

Future studies should focus on a longitudinal evaluation of lung function in SCA patients from sub-Saharan Africa, ideally including static lung volumes measured and accurate information about every aspect of clinical history that may influence respiratory outcomes. Another important area of research is the impact of comprehensive care programmes and therapeutic interventions, such as hydroxyurea, on long-term respiratory outcomes of SCA patients in low-resource settings.

\section{CONCLUSIONS}

Paediatric patients with SCA living in West Africa and followed at a tertiary care centre had more impaired lung function than their counterparts in the UK, showing significantly lower $\mathrm{FEV}_{1}$ and $\mathrm{FVC} \mathrm{z}$-scores and higher prevalence of a restrictive spirometry pattern. Wasting affected almost a third of Nigerian patients and was associated with lower dynamic lung volumes and increased risk of restrictive spirometry. In light of the high burden of respiratory impairment in children with SCA in West Africa, lung function assessment should be implemented in this setting to identify early patients with lung end-organ damage, who could benefit from closer follow-up and more aggressive therapies.

\section{Author affiliations}

${ }^{1}$ Department of Medicine, Division of Pediatrics, University Hospital of Udine, Udine, Italy

${ }^{2}$ Institute of Hygiene and Clinical Epidemiology, University Hospital of Udine, Udine, Italy

${ }^{3}$ Department of Pediatrics, Barau Dikko Teaching Hospital, Kaduna State University, Kaduna, Nigeria

${ }^{4}$ Department of Hematology, Barau Dikko Teaching Hospital, Kaduna State University, Kaduna, Nigeria

${ }^{5}$ Respiratory, Critical Care and Anaesthesia Section, III Programme, Great Ormond Street Institute of Child Health, University College London, London, UK

${ }^{6}$ University of Trieste, Trieste, Italy

${ }^{7}$ Department of Surgical Sciences, Dentistry, Gynecology and Pediatrics, Pediatric Division, University of Verona, Verona, Italy

${ }^{8}$ Department of Paediatric Haematology, Evelina London Children's Hospital, Guy's and St Thomas' NHS Trust, London, UK

${ }^{9}$ Department of Pediatric Respiratory Medicine, King's College Hospital NHS Foundation Trust, London, UK

Twitter Emma Raywood @fizzy_emma and Ashel Dache Sunday @ashelusher

Acknowledgements We thank Dr RC Audu, Dr Z Sani and Dr H Dadan-Garba from the Barau Dikko Teaching Hospital, Kaduna, Nigeria, for their help with data collection in Nigeria. We thank 'SCORE International' and 'A.L.P.I. associazione allergie pneumopatie infantile' for their financial support to the study.

Contributors MA conceived the study, performed data collection, interpreted data and wrote the manuscript; $B \mathrm{BI}$ and $\mathrm{PC}$ conceived the study and contributed to the manuscript; MA, RZ, LGD, CZ, KV, EP, ADS and SN performed data collection and contributed to the manuscript; LC performed statistical analysis, interpreted data and contributed to the manuscript; ER, AG and MCC interpreted data and contributed to the manuscript. All the authors approved the final draft of the manuscript.

Funding 'Sickle Cell Cohort Research Foundation' (www.scorecharity.com) and 'A.L.P.I. associazione allergie pneumopatie infantile' (https://alpiassociazione.it/) offered financial support to refund travel expenses to Nigeria for two investigators (MA and $\mathrm{CZ}$ ) and to buy a mobile spirometer that was used for data collection and was donated to the local hospital in Nigeria at the end of the study.

Competing interests None declared.

Patient consent for publication Obtained.

Ethics approval This cross-sectional multicentre study was conducted under approval by the local ethics committees in Nigeria (HREC 16-0017) and in the UK (REC 12/SW/0319).

Provenance and peer review Not commissioned; externally peer reviewed. Data availability statement Data are available on reasonable request.

\section{ORCID iDs}

Michele Arigliani http://orcid.org/0000-0002-5366-4594

Emma Raywood http://orcid.org/0000-0002-0993-5115

\section{REFERENCES}

1 Mehari A, Klings ES. Chronic pulmonary complications of sickle cell disease. Chest 2016;149:1313-24.

2 Piel FB, Patil AP, Howes RE, et al. Global epidemiology of sickle haemoglobin in neonates: a contemporary geostatistical model-based map and population estimates. Lancet 2013;381:142-51.

3 Lunt A, McGhee E, Sylvester K, et al. Longitudinal assessment of lung function in children with sickle cell disease. Pediatr Pulmonol 2016;51:717-23.

4 MacLean JE, Atenafu E, Kirby-Allen M, et al. Longitudinal decline in lung volume in a population of children with sickle cell disease. Am J Respir Crit Care Med 2008;178:1055-9.

5 Bendiak GN, Mateos-Corral D, Sallam A, et al. Association of wheeze with lung function decline in children with sickle cell disease. Eur Respir J 2017:50:1602433.

6 Field JJ, Glassberg J, Gilmore A, et al. Longitudinal analysis of pulmonary function in adults with sickle cell disease. Am J Hematol 2008;83:574-6.

7 Kassim AA, Payne AB, Rodeghier M, et al. Low forced expiratory volume is associated with earlier death in sickle cell anemia. Blood 2015;126:1544-50.

8 Cohen RT, Strunk RC, Rodeghier M, et al. Pattern of lung function is not associated with prior or future morbidity in children with sickle cell anemia. Ann Am Thorac Soc 2016;13:1314-23.

9 Arteta M, Campbell A, Nouraie M, et al. Abnormal pulmonary function and associated risk factors in children and adolescents with sickle cell anemia. J Pediatr Hematol Oncol 2014;36:185-9.

10 Koumbourlis AC, Zar HJ, Hurlet-Jensen A, et al. Prevalence and reversibility of lower airway obstruction in children with sickle cell disease. J Pediatr 2001;138:188-92. 
11 Sylvester KP, Patey RA, Milligan P, et al. Impact of acute chest syndrome on lung function of children with sickle cell disease. J Pediatr 2006;149:17-22.

12 Adegoke SA, Kuti BP, Omole KO, et al. Acute chest syndrome in sickle cell anaemia: higher serum levels of interleukin-8 and highly sensitive C-reactive proteins are associated with impaired lung function. Paediatr Int Child Health 2018;38:244-50.

13 Arigliani $\mathrm{M}$, Kitenge $\mathrm{R}$, Castriotta $\mathrm{L}$, et al. Lung function in children with sickle cell disease from central Africa. Thorax 2019;74:604-6.

14 Stewart Jodi-Anne T, Willen SM, Cohen R, et al. BMI percentile is an independent predictor of increase in lung function in children with sickle cell anemia. Am J Hematol 2019;94:E136-8.

15 Cook J, Jefferis O, Matchere P, et al. Sickle cell disease in Malawian children is associated with restrictive spirometry: a cross-sectional survey. Int J Tuberc Lung Dis 2013:17:1235-8.

16 VanderJagt DJ, Trujillo MR, Jalo I, et al. Pulmonary function correlates with body composition in Nigerian children and young adults with sickle cell disease. J Trop Pediatr 2008; 54:87-93.

17 Dormandy E, James J, Inusa B, et al. How many people have sickle cell disease in the UK? J Public Health 2018;40:e291-5.

18 Galadanci N, Wudil BJ, Balogun TM, et al. Current sickle cell disease management practices in Nigeria. Int Health 2014;6:23-8.

19 Lum S, Bountziouka V, Sonnappa S, et al. Lung function in children in relation to ethnicity, physique and socioeconomic factors. Eur Respir J 2015;46:1662-71.

20 Miller MR, Hankinson J, Brusasco V, et al. Standardisation of spirometry. Eur Respir J 2005;26:319-38.

21 Kirkby J, Welsh L, Lum S, et al. The EPICure study: comparison of pediatric spirometry in community and laboratory settings. Pediatr Pulmonol 2008:43:1233-41.

22 Ballas SK, Lieff S, Benjamin LJ, et al. Definitions of the phenotypic manifestations of sickle cell disease. Am J Hematol 2010;85:6-13.

23 Boyce $W$, Torsheim T, Currie $C$, et al. The family affluence scale as a measure of national wealth: validation of an adolescent self-report measure. Soc Indic Res 2006;78:473-87.

24 Pan $\mathrm{H}$, Cole TJ. (last). LMSgrowth, a Microsoft Excel add-in to access growth references based on the LMS method. Version 2.77, 2012. Available: http://www. healthforallchildren.com/ [Accessed 19 Jun 2018].

25 WHO. Growth reference data for 5-19 years. WHO. Available: http://www.who.int growthref/en/ [Accessed 19 Jun 2018].

26 Quanjer PH, Stanojevic S, Cole TJ, et al. Multi-ethnic reference values for spirometry for the 3-95-yr age range: the global lung function 2012 equations. Eur Respir J 2012:40:1324-43.
27 Pellegrino R, Viegi G, Brusasco V, et al. Interpretative strategies for lung function tests. Eur Respir J 2005:26:948-68.

28 Lunt A, Desai SR, Wells AU, et al. Pulmonary function, CT and echocardiographic abnormalities in sickle cell disease. Thorax 2014:69:746-51.

29 Klings ES, Wyszynski DF, Nolan VG, et al. Abnormal pulmonary function in adults with sickle cell anemia. Am J Respir Crit Care Med 2006:173:1264-9.

30 Knight-Madden JM, Forrester TS, Lewis NA, et al. The impact of recurrent acute chest syndrome on the lung function of young adults with sickle cell disease. Lung 2010;188:499-504.

31 DeBaun MR, Strunk RC. The intersection between asthma and acute chest syndrome in children with sickle-cell anaemia. Lancet 2016:387:2545-53.

32 Fullman N, Yearwood J, Abay SM, et al. Measuring performance on the healthcare access and quality index for 195 countries and territories and selected subnational locations: a systematic analysis from the global burden of disease study 2016. Lancet 2018:391:2236-71.

33 Looijmans-van den Akker I, van Luijn K, Verheij T. Overdiagnosis of asthma in children in primary care: a retrospective analysis. Br J Gen Pract 2016:66:e152-7.

34 Adeloye D, Chan KY, Rudan I, et al. An estimate of asthma prevalence in Africa: a systematic analysis. Croat Med J 2013;54:519-31.

35 Willen SM, Cohen R, Rodeghier M, et al. Age is a predictor of a small decrease in lung function in children with sickle cell anemia. Am J Hematol 2018:93:408-15.

36 Chaudry RA, Rosenthal M, Bush A, et al. Reduced forced expiratory flow but not increased exhaled nitric oxide or airway responsiveness to methacholine characterises paediatric sickle cell airway disease. Thorax 2014:69:580-5.

37 McLaren A, Klingel M, Behera S, et al. Effect of hydroxyurea therapy on pulmonary function in children with sickle cell anemia. Am J Respir Crit Care Med 2017;195:689-91.

38 Cox SE, Makani J, Fulford AJ, et al. Nutritional status, hospitalization and mortality among patients with sickle cell anemia in Tanzania. Haematologica 2011:96:948-53.

39 Arigliani M, Spinelli A, Liguoro I, et al. Nutrition and lung growth. Nutrients 2018;10:919.

40 Ong BA, Caboot J, Jawad A, et al. Respiratory muscle force and lung volume changes in a population of children with sickle cell disease. $\mathrm{Br} J$ Haematol 2013:163:112-7.

41 Heinzerling AP, Guarnieri MJ, Mann JK, et al. Lung function in woodsmoke-exposed Guatemalan children following a chimney stove intervention. Thorax 2016:71:421-8.

42 Cook DG, Strachan DP, Carey IM. Health effects of passive smoking. 9. Parental smoking and spirometric indices in children. Thorax 1998:53:884-93. 